\title{
La (est)ética del hambre en el Período Especial
}

\author{
(Aesth)ethics of Hunger in the Special Period
}

A (est)ética da fome no Período Especial

\section{Rita De Maeseneer}

UNIVERSITEIT ANTWERPEN, BÉLGICA

Profesora de Literatura hispanoamericana en la Universidad de Amberes,

Bélgica. $\mathrm{PhD}$ en Literatura, Universidad de Gante. Autora de $E l$

festín de Alejo Carpentier: una lectura culinario-intertexual (Genève:

Droz, 2003), Encuentro con la narrativa dominicana contemporánea

(Madrid/Frankfurt: Iberoamericana/Vervuert, 2006), Seis ensayos

sobre narrativa dominicana contemporánea (Santo Domingo: Banco

Central de la República Dominicana, 2011), Devorando a lo cubano:

una aproximación gastrocrítica a textos relacionados con el siglo XIX

y el Período Especial (Madrid/Frankfurt: Iberoamericana/Vervuert,

2012). Co-autora de Ocho veces Luis Rafael Sánchez (Madrid: Verbum,

2008). Correo electrónico: rita.demaeseneer@uantwerpen.be

\section{Artículo de reflexión}

Este artículo se publicó originalmente en inglés como De Maeseneer, Rita. "The Aesthetics of Hunger and the Special Period in Cuba". Caribbean Food cultures: Culinary practices and consumption in the Caribbean and its diáspora. Eds. Wiebke Beushausen, Anne Brüske, Ana-Sofia Commichau, Patrick Helber y Sinah Kloß. Bielefeld: Transcript, 2014. 27-48. Impreso.

Documento accesible en línea desde la siguiente dirección: http://revistas.javeriana.edu.co

doi: 10.11144/Javeriana.cl20-39.ehpe 


\section{Resumen}

En las dos últimas décadas muchos autores y cineastas residentes dentro o fuera de Cuba se han referido al contexto del Período Especial en sus creaciones artísticas. En este ensayo quisiera reflexionar sobre las modalidades de la representación del hambre, su exploración e incluso explotación. El análisis de un corpus de películas y novelas que se relacionan con el Período Especial propone cuatro «estrategias» que se alejan cada vez más del mundo referencial marcado por la penuria: estereotipo, contraste, relegación al segundo plano, metonimia (en el sentido de desplazamiento).

El análisis revela que estas diferentes « estrategias » sirven objetivos específicos en el campo de la ética, la estética y la poética de estas expresiones artísticas.

Palabras clave: literatura cubana contemporánea, cine cubano contemporáneo, Food Studies

\section{Abstract}

During the last two decades, a number of authors and filmmakers, residing in or outside Cuba, have made reference to the context of the Special Period in their artistic creations. This essay wants to propose a reflection on the representation modalities of hunger, its exploration, and even, exploitation. The analysis of a corpus of films and novels related to the Special Period proposes four «strategies» each one further away from the referential world marked by scarcity: stereotype; contrast; pushing into the background; metonymy (meaning displacement). The analysis reveals that these different «strategies» work towards specific purposes in the field of ethics, aesthetics, and poetics of these artistic expressions.

Keywords: contemporary Cuban literature; contemporary Cuban cinema; food studies

\section{Resumo}

Nas últimas duas décadas muito autor e cineasta residente em Cuba ou no exterior se referiu ao contexto do Período Especial nas suas criações artísticas. Neste ensaio eu gostaria de refletir sobre as modalidades da representação da fome, sua compreensão e mesmo exploração. A análise de um corpus de filmes e romances relacionadas com o Período Especial propõe quatro «estratégias» que vão para longe, cada vez mais do mundo referencial marcado pela penúria: estereotipo, contraste, relegação para o segundo plano, metonímia (no sentido de deslocamento). A análise desvenda que tais diferentes « estratégias » servem objetivos específicos no campo da ética, a estética e a poética destas expressões artísticas.

Palavras-chave: literatura cubana contemporânea; cinema cubano contemporâneo; Food Studies 
EN SU ENSAYO fundacional de 1964, "Problemática de la actual novela latinoamericana", Alejo Carpentier reflexionó sobre los diferentes contextos necesarios para la praxis circundante en la novela. Aparte de los contextos culturales, políticos, raciales, económicos, ideológicos, espaciales... incluye también los contextos culinarios. He copiado el inicio del apartado:

[Los contextos culinarios]Tienen una importancia en cuanto a sus particulares contextos históricos. El ajiaco cubano, por ejemplo, plato nacional de la cocina criolla, reúne, en una misma cazuela, la cocina de los españoles - la que traía Colón en sus naves-, con productos (las "viandas" llaman todavía a eso) de la primera tierra avistada por los descubridores. Después la cocina española se llamó el bucán porque unos aventureros franceses, por ello llamados bucaneros, se dieron a sistematizar en Cuba la industria elemental consistente en solear, ahumar y salar carnes de venado y de cerdos jíbaros. (Carpentier 22)

En este fragmento Carpentier alude a varios campos de las ciencias humanas que son importantísimos a la hora de estudiar el discurso culinario. Insiste primero en la dimensión diacrónica de la comida. Sabemos que a partir de la creación de l'Ecole des Annales, los historiadores se propusieron ir más allá de la historia militar, política y diplomática, y acercarse a la vida cotidiana y a la llamada cultura material dentro de una historia de las mentalidades. Luego, Carpentier pasa a la connotación identitaria. En Cuba lo identitario es mezcla de diferentes razas, tal como lo expuso el antropólogo Fernando Ortiz mediante el símbolo del ajiaco, este plato compuesto por ingredientes provenientes de varios continentes que Carpentier retoma aquí. Se enfatizan aquí únicamente las vertientes española y la indígena, aunque la impronta africana y la china (en menor medida) también han sido decisivas en la cocina cubana. Además, quien dice raza dice clase social. Sociólogos como Pierre Bourdieu en La distinction: critique sociale du jugement o Michel de Certeau en L'invention du quotidien estudiaron respectivamente la oposición entre cantidad y calidad según la clase social y la alimentación cotidiana como parte del capital cultural de cada clase social. Luego, al comentar la manera de preparar las carnes, el escritor cubano parece hacer eco a las tesis de Claude Lévi-Strauss sobre las diferentes maneras de preparar comida y sus implicaciones para el grado de civilización, tales como las resumió el antropólogo en "Le triangle culinaire". La manera de preparar implica mayor o menor cercanía a la naturaleza o la cultura, o, si se quiere recurrir a un tropo muy conocido en el contexto latinoamericano desde que lo acuñó Sarmiento, expresa civilización o barbarie. 
Por tanto, Carpentier era muy consciente de las múltiples connotaciones que implican las referencias culinarias y sugiere que varios campos de las ciencias humanas son necesarios para estudiar los contextos culinarios.

A diferencia del mundo cinematográfico donde se han trabajado mucho los food films, en el ámbito literario como tal no existe realmente un marco teórico, aunque se han publicado bastantes análisis que formulan observaciones interesantes a partir de las remisiones culinarias. Pienso en los estudios de Ada Teja sobre la obra de Lezama Lima, de Alicia Vadillo sobre Sarduy y mis propios intentos de hincar el diente a la obra de Carpentier. Los críticos se apoyan a menudo en L'oeuvre de François Rabelais et la culture populaire au Moyen Age et sous la Renaissance de Bakhtin. Son fundacionales sus reflexiones sobre la relación entre comida, abundancia, celebración del trabajo, proyección hacia el futuro, fiesta y alegría, triunfo de la vida, del cuerpo y de la sexualidad sobre la muerte. También se echa mano de las observaciones de Barthes para quien la comida es un sistema de comunicación, un conjunto de usos, situaciones y comportamientos; en otras palabras, la comida significa. En su introducción a la reedición en 1975 de Physiologie du goût de Brillat-Savarin, Barthes propone una "Lecture de Brillat-Savarin" (303-326). Barthes medita sobre temas como la relación entre la alimentación y lo materno, comida y erotismo, comer y hablar, la relevancia de las sensaciones y el consiguiente hedonismo, lo líquido frente a lo sólido, la relación entre comida y clase social. En 1990, Ronald Tobin acuñó el término gastrocrítica en su libro Tarte à la crème: Comedy and Gastronomy in Molière's Theater. En un ensayo ulterior de 2002, titulado "Qu'est-ce que la gastrocritique?", la definió de la siguiente manera, como un subgrupo de la sociocrítica:

Cette méthode suppose une vaste entreprise de recherche dans les sciences humaines qui explore les liens entre l'alimentation et l'art. Elle appartient et fait appel à l'histoire - histoire culturelle, histoire économique, histoire des mentalités et de la vie quotidienne, et histoire de l'art-, à la sociologie, à la civilité et la galanterie, à l'alimentation et les livres de cuisine, à la médecine, la nutrition et les questions diététiques et de santé, à la critique littéraire et la sémiotique, à la psychanalyse et la philosophie, aux études de la femme et, surtout à l'anthropologie. La gastrocritique est conçue pour mettre en relief le fait que le poète et le cuisinier travaillent tous deux à créer la métamorphose et l'illusion. (624-625)

La definición de Tobin presenta bastantes semejanzas con las ideas de Carpentier. Me interesa detenerme en el final, cuando compara al poeta/creador con el cocinero, porque ambos crean una ilusión. Efectivamente, escribir y cocinar 
son dos operaciones similares. En una entrevista con Rita Guibert, García Márquez lo corrobora, ya que dice: "Sé exactamente cómo La hojarasca fue derecho de mis tripas al papel. Los otros textos también me salieron de ahí, pero ya había hecho mi aprendizaje... Los trabajé, los cociné, los sazoné..." (García Márquez 326). El escritor suele conformar un texto elaborado en su "cocina de la escritura", para citar las palabras de la escritora puertorriqueña Rosario Ferré (Ferré). Además, la representación del alimento nos hace asistir a la eterna pugna entre el texto como entidad referencial (la mimesis) y el texto como entidad autónoma y autorreferencial (la imitatio). O dicho con dos frases "biensonantes": Les mets ne sont pas les mots (Jeanneret) / The Word is not the World. Por tanto, no es suficiente inventariar las connotaciones engendradas por las remisiones culinarias, sino que hay que interpretarlas dentro de la poética de cada escritor.

Teniendo en mente este marco general, quisiera comentar algunas expresiones literarias y cinematográficas que evocan la Cuba de los noventa. Es sabido que, desde el Descubrimiento, el Caribe y Cuba en particular han venido asociándose a azúcar y dulzura, tanto de sus productos como de sus habitantes. También ha sido subrayada la importancia de raíces comestibles como la yuca o el boniato y la carne, sobre todo el puerco y el pollo. El elemento esencial en la imaginación de la comunidad cubana son las frutas tropicales como la guanábana, el caimito, el mamey y la reina de todas esas frutas tropicales: la piña. Las islas caribeñas han sido evocadas numerosas veces en su abundancia exótica/sensual, aunque la carencia tal vez estuviera más cerca de la realidad.

$\mathrm{Al}$ inicio de los noventa del siglo pasado, esta dulzura se convirtió más bien en amargura. Como es sabido, en esa década se instauró el "Período Especial en tiempos de paz" debido al derrumbe del bloque soviético, lo cual implicó recortes de comida y transporte. Las autoridades ya no eran capaces de asegurar los servicios mínimos y tampoco lograron cumplir con las cuotas estipuladas en la libreta de racionamiento que solía incluir una serie de productos básicos como arroz, café, jabón, pan, huevo, leche, etc... La situación fue remediada en parte gracias a la economía paralela en dólares, el aumento de la iniciativa privada, ma non troppo, el envío de remesas, el desarrollo del turismo, la "plantación de hoteles" en las palabras de Benítez Rojo (98) y el turismo sexual. Para los escritores la situación también se volvió insostenible a causa de la escasez de papel, de manera que se les permitió publicar en editoriales extranjeras desde noviembre de 1993 y a los cineastas se les autorizó hacer coproducciones con el extranjero. Hacia mediados de los noventa la situación mejoró un tanto (para los que tenían más que pesos cubanos, sobre todo). No obstante, hasta hoy en día los cubanos siguen en la lucha, tienen que "inventar" y "resolver", es decir improvisar, para 
encontrar soluciones a los problemas de subsistencia y sobrevivencia día tras día. El verbo inventar implica a nivel culinario a veces sustituir ciertos productos inalcanzables por Ersatz, cuyo sabor se asemeja a los ingredientes identitarios.

Cabe observar que los cubanos ya antes habían pasado por épocas difíciles, que algunos consideran otros tantos "períodos especiales", pero la de los noventa fue muy impactante. Por eso, me parece sumamente significativo que en una película concebida desde 1988, pero no terminada hasta 1991, justo en el umbral del derrumbe, algunas escenas culinarias anticipen evoluciones ulteriores. Me refiero a la película controvertida Alicia en el pueblo de Maravillas de Daniel Díaz Torres, una sátira de la burocracia en la sociedad cubana, porque los habitantes de Maravillas aceptan todas las reglas estúpidas que se les imponen. Aunque la comida no es el tema central, su representación es muy relevante, hasta visionaria, diría. Por ejemplo, en una escena situada en un restaurante de Maravillas, la película anuncia la doble economía y la separación entre turistas y cubanos. Los nacionales se ven obligados a comer espaguetis con huevos. Usan cubiertos encadenados a la mesa para que no los roben y se ve que algunas cadenas son demasiado cortas. Además, la camarera tiene un delantal con un estampado de huevo frito. Esta tela parece ser ubicua en la película. Una de las explicaciones es que apunta a las penurias en el abastecimiento que obligan a la gente a sobrevivir en base a este plato elemental, casi siempre asequible, incluso en tiempos de escasez.

Más allá de esta película precursora, resulta que en los noventa y en la primera década del siglo XXI muchas películas y obras literarias de dentro y de fuera de la isla evocan los problemas del Período Especial en mayor o menor medida. Visto el silencio completo de la prensa cubana de dentro, se podía constatar como una urgencia de testimoniar sobre este contexto especialmente duro, en el que las penurias alimenticias estaban muy presentes. Los escritores y cineastas incorporaron esta base referencial en sus expresiones artísticas. A partir de un corpus de películas y novelas de las dos últimas décadas propongo presentar algunas "estrategias" recurrentes para enfrentarse a esta "realidad" mediante algunos de los ejemplos más significativos. Las he designado mediante los siguientes rótulos: estereotipo, contraste, relegación al segundo plano y metonimia (en el sentido de desplazamiento). Comentaré estas "estrategias" en este orden, porque implican un alejamiento mayor (o al menos distinto) de la base referencial. Intentaré mostrar que estas diferentes estrategias obedecen a propósitos específicos de los artistas en el campo de la ética, poética y estética en su enfrentamiento al hambre referencial.

Una primera estrategia para acercarse al Período Especial consiste en usar algunas manifestaciones espectaculares de la escasez que se han convertido en estereotipos. En "Literatura versus lechuguitas: breve esbozo de una tendencia", 
Ena Lucía Portela, escritora residente en Cuba, nos presenta una lista de lo que los editores extranjeros consideran como la "realidad cubana", que ella tendría que incorporar a su obra para vender: "El período especial, los apagones, la miseria, el picadillo de soya, los balseros, las jineteras, la cosa gay, la brujería, la guerra de Angola... tú sabes, esas cosas" (73). El mercado pide un color local que Portela define como una estética folklórica de escasez. Por tanto, se construyen una serie de tópicos auto-exóticos, lo que Ester Whitfield llama Special Period Fiction.

En lo alimentario Portela menciona el picadillo de soya. Desde arriba, las autoridades lo proporcionaron como sustituto de la carne a los cubanos carnívoros. "Picadillo de soya" es el título de una canción de 1994 de NG La Banda, donde en una especie de choteo se atribuyen a este OCNI, objeto de comida no comestible, todas las vitaminas y calorías posibles. Desde abajo, el pueblo cubano también buscó ansiosamente imitaciones de carne. El ejemplo más estrambótico es el bistec de frazada. Muchas obras, predominantemente realizadas fuera de Cuba, incluyen estos tópicos (auto)exóticos de la penuria como en Havana lunar de Robert Arellano, un cubano-americano nacido en 1969, y en Ruins de Achy Obejas, novela situada en 1994, donde el bistec de frazada es un leitmotiv. En Youtube hay una parodia del programa de la cocinera oficial de Cuba, Nitza Villapol, en el que se explica la preparación de este bistec. Volveré sobre la importancia de la papesa de la cocina.

Sea como sea, los cubanos carnívoros, sobre todo los habitantes de La Habana, estaban ansiosos por encontrar carne de puerco, sobre todo con vistas a la preparación del idiosincrático lechón para Navidad. Por eso empezaron a criar cerdos en los apartamentos. Algunos textos evocan esta realidad, por ejemplo, los cuentos "César" de Nancy Alonso, residente en Cuba, y "Macho grande en el balcón" del autor cubano residente en Suecia desde 1975, René Vázquez Díaz. En ambos cuentos el acento está en lo domesticable de los cerdos que son invariablemente humanizados. Incluso llevan nombre propio (Macho Grande, César). Siempre se percibe la misma evolución: debido a la cerdofilia no se mata al cerdo para consumo. Es como si no se atrevieran a matar la quintaesencia de lo cubano metaforizado en el cerdo. Es otro ejemplo del Special Period Exotic.

Vemos por tanto que muchas expresiones artísticas crean un imaginario culinario que selecciona y privilegia algunos tópicos (auto)exóticos del Período Especial. Aparte del uso de estereotipos, se recurre a otra estrategia exitosa, la contrastiva, muchas veces combinada con exageración. Es lo que aplica Zoé Valdés en Te di la vida entera de 1996. Valdés nació en Cuba en 1959 y se exilió definitivamente en Francia en 1995, convirtiéndose en una feroz anticastrista. La 
obra narra la vida de una mujer, Caridad [Cuca] Martínez, y del mafioso Juan Pérez, el Uan. Este la abandona dejándole una hija, María Regla, que nace en 1959. La novela donde Cuca espera toda su vida es una mezcla de melodrama y de realismo sucio, combinada con ironía y humor. El libro es un despiadado ajuste de cuentas con el régimen de Castro, el Comediante en Jefe o Talla Super Extra (XXL) en la narración.

Una de las maneras de atacar el régimen es oponiendo la supuesta abundancia de la época prerrevolucionaria a la penuria durante la Revolución, y en particular en los noventa. La narradora recuerda las delicias de la comida identitaria integrando dos páginas de descripciones detalladas de recetas de la Cuba de antes, parodiando así el discurso feminista al estilo de Laura Esquivel. Por ejemplo, incorpora con nostalgia la receta de los frijoles negros a lo Valdés Fauly. Es una copia casi textual del libro de cocina prerrevolucionario de Nitza Villapol. Villapol había escrito antes de 1959 varios libros de cocina que después "purificó" eliminando referencias a productos norteamericanos y ciertas recetas, por ejemplo, los frijoles a lo Valdés Fauly. Después de la Revolución, Villapol se convirtió en el icono del régimen, fue la María Auxiliatrix de Fidel en las palabras de Vázquez Montalbán (46) y dominaba la televisión cubana con su programa de cocina. Al reproducir recetas de los libros de cocina prerrevolucionarios de Villapol, la metonimia de Castro, Zoé Valdés lo ataca de manera virulenta. El método contrastivo es usado igualmente en las novelas detectivescas de Leonardo Padura Fuentes, pero no está al servicio de un ataque frontal al régimen político, sino que más bien se constata el fracaso económico. Además, la carencia frente a la opulencia adquiere resonancias más profundas: apunta a un vacío ontológico en el personaje de Mario Conde cuya libertad individual es opuesta a la coerción colectiva (Wilkinson 208).

En el otro extremo del espectro que estoy esbozando se encuentra el recurso de la relegación al trasfondo, como tercera estrategia. Se efectúa casi un olvido de los problemas de sustento, que son tratados de manera tangencial. Es el caso de Silencios de Karla Suárez, novela escrita antes de que la autora saliera del país en 1999. Este Bildungsroman particular se concentra en una muchacha rockera, apodada la Flaca, en los ochenta y al inicio de los noventa (hasta 1994). Su sobrenombre parece sugerir que la manutención no es su mayor preocupación. Lo que sí importa es la búsqueda del sentido de la vida desde un planteamiento individual, a la vez que se indaga en las modalidades de expresión: mentir (no decir), callarse, expresarse escribiendo, cantando o pintando, sonreír en lugar de contestar en situaciones molestas. Poco influye el entorno social en esta novela volcada hacia el interior del individuo. Con tal de que la adolescente encuentre 
alcohol para compartirlo con sus amigos, no le interesan mucho los problemas con los que lidia la sociedad cubana. Así la Flaca se limita a constatar la monotonía de los platos de arroz y chícharos, sin relacionarlos con los problemas causados por el Período Especial. Al final de la novela, cuando todos sus amigos se han ido del país, se encierra en su casa, esperando la nada.

Como en una especie de puesta en abismo, la protagonista se da cuenta del distanciamiento respecto a los temas facilitados por el Período Especial. Con motivo de las discusiones de sus amistades artísticas sobre la literatura, la narradora formula la siguiente reflexión:

No sé si sería la carencia de un periodismo verdadero, pero se me antojaba que los escritores hacían periodismo. Nadie contaba historias. Todos decían lo que yo podía ver con sólo asomar las narices fuera de mis paredes. Hablaban de gente fugándose en balsa de la isla,jineteras en las noches de La Habana, el dólar que subía y subía, la esperanza que bajaba y bajaba. Resultaba aburrido. (Suárez 244)

El alejamiento de lo circundante y la búsqueda existencial caracterizan asimismo el mediometraje Madagascar, filmado en el crítico año de 1994 por Fernando Pérez. La crisis económica por la que atraviesa el país no está ausente, por ejemplo, en los planos generales de una ciudad derruida, que es otro cliché del Special Period Exotic. No obstante, la película no enfatiza las necesidades materiales, sino que enfoca el conflicto entre la madre y la hija que quiere viajar a Madagascar, símbolo de lo espiritual para la hija. No es una casualidad que hacia el final de la película se nos presente una escena de tintes oníricos en la que una serie de personas comen de platos de arroz blanco ante una larga mesa llena de coles. Es una alegoría de la vida automatizada, volcada exclusivamente sobre lo exterior y lo material, de la que Laurita quiere escapar, en vano. Toda la película presenta una manera bien particular de alejarse de los temas consabidos del Período Especial.

La escritora Ena Lucía Portela, residente en la isla, también dedica poca atención a los problemas de sustento en su novela La sombra del caminante, a pesar de que está ubicada a finales de los noventa. En esta novela, muy complicada a nivel de narración, contenido y estilo, se medita sobre temas como raza, culpa, gender, literatura, violencia y mal. La dimensión referencial no importa mucho en la totalidad. Por tanto, no está en el punto de mira el Período Especial y nunca se insiste en la escasez como tal. No impide que aparezca de manera alusiva y tangencial. Así el único plato de la protagonista mencionado a lo largo del libro es marpacíficos con cebolla. Ser vegetariano en la Cuba tan dada a degustar carne 
ya es toda una hazaña y una provocación. A la vez, apunta de manera indirecta a la falta de víveres. Otro fragmento en que la narradora remite de manera sutil a la escasez es cuando describe la reacción de los cubanos ante una conocida escena culinaria en Fanny y Alexander de Ingmar Bergman: el público se echa a reír, porque "los cinéfilos habaneros se reían de todo lo relacionado con el verbo comer" (Portela, La sombra del caminante 94). Es la típica forma de resistencia de los cubanos conocida como choteo, como una manera de bregar con contratiempos de índole culinaria.

Otros escritores sí integran remisiones al entorno, pero rebasan el nivel mimético, hiperbólico y contrastivo de enfrentarse al hambre. La carencia, a veces en su modalidad estereotipada, constituye un punto de partida para un cuestionamiento de índole ontológica y/o filosófica. Es lo que he designado como una estrategia de metonimia (en el sentido de desplazamiento). Así Ronaldo Menéndez, exiliado en Madrid desde 2004, usa la cría del puerco tan estereotípica como un punto de partida para una reflexión sobre el mal en su novela de 2006, Las bestias. Al igual que en los dos cuentos que comenté ("César" y "Macho Grande en el balcón"), el cerdo criado por un profesor de filosofía del arte en su bañera es a veces humanizado. No obstante, el movimiento inverso, la animalización de los personajes, es mucho más frecuente. Así el protagonista, un profesor, es calificado de "bípedo implume" (Menéndez 62). Cuando el profesor se entera por mera casualidad que dos hombres lo persiguen para asesinarlo, llega a cautivar a uno de ellos, llamado Bill. El profe encierra a Bill, a quien le da el apodo de "Lo Negro", en la bañera donde es cebado el cerdo. El cerdo se convertirá en el principal instrumento de tortura de Bill. Dice el profesor:

¿Sabes lo que hay allá adentro? (señalando al baño). Y sin esperar respuesta: Un puerco, es decir, una máquina de devorar todo lo que no sea su propio cuerpo. Si no me dices lo que quiero saber, tendrás que convivir con él de aquí en adelante. [...]. Y lo que es aún más singular, lleva tres días sin alimentarse, o sea que en cuanto te vea entrar decidirá que eres su evidente alimento. (87)

El cerdo no tiene sobrenombre humano como en los cuentos que señalé, sino que es cosificado mediante la perífrasis de "la máquina de devorar todo lo que no sea su propio cuerpo". El puerco amenaza constantemente a Bill, "Lo Negro", quien primero tiene que compartir el sancocho del animal y finalmente será devorado por el animal hambriento, porque el profesor deja de suministrar comida. La crianza de un cerdo sirve por tanto de punto de partida para generar reflexiones sobre el mal, el racismo, la frontera entre lo humano y lo animal, civilización y barbarie, el sadomasoquismo. 
Otro autor que va más allá de los clichés es Pedro Juan Gutiérrez, aunque muchos lo han considerado como el ejemplo por antonomasia del Special Period Exotic. En su ciclo de Centro Habana evoca en un lenguaje descarnado un ambiente violento donde prevalece el sexo y son transgredidas las normas socio-éticas. Según críticos como Guillermina de Ferrari, esta poética de realismo sucio constituiría su manera de responder a la crisis de los noventa y de exacerbar la individualidad sin pensar en el mañana o en las grandes utopías colectivas, tan típicas de la Revolución (De Ferrari).

Es cierto que están presentes figuras y tópicos del Período Especial: jineteras, la fascinación con el sexo y la carne mulata/negra, las manifestaciones de magia. No obstante, creo que hay más que "pingas, semen y bollos" o crítica del régimen, al menos en algunos libros suyos, por ejemplo, El Rey de La Habana. El protagonista Rey vive en la pobreza con su madre y su hermano. Siendo acusado injustamente de haber matado a su madre, lo encierran en un correccional de menores. Se evade y luego sobrevive, a veces robando, pero la mayor parte del tiempo lo mantienen unas mujeres/prostitutas a quienes paga con sexo. Rey es un muertodehambre, un marginado de cualquier sistema, no solo del cubano, aunque la novela se ubica claramente en el Período Especial y se pueden encontrar alusiones al contexto especial de Cuba.

Al igual que en otras novelas de Gutiérrez abundan los maratones sexuales, la violencia, lo abyecto. Rey hace incluso el amor con el cadáver de la mujer que más ha amado, llamada Magda, después de golpearla a muerte. Su vida es una lucha por la sobrevivencia, que Quintero Herencia llama un "darwinismo tropical" (23). De esta manera se cuestiona la frontera entre lo humano y lo animal. Esto también se puede aplicar a las referencias a su comida de pobre. Rey come como un animal las cosas que encuentra en la calle, casi no sabe comer en una mesa. Incluso se traga el sancocho de un puerco. Muy significativamente morirá después de que le han contagiado de rabia unas ratas hambrientas y el cuerpo de Rey será comido por las auras tiñosas. Leamos el final del libro:

Su cuerpo ya se podría por las úlceras producidas por las ratas. El cadáver se corrompió en pocas horas. Llegaron las auras tiñosas. Y lo devoraron poco a poco. El festín duró cuatro días. Lo devoraron lentamente. Cuanto más se podría, más les gustaba aquella carroña. Y nadie supo nada jamás. (Gutiérrez 218)

Aunque la isotopía sexual es la que más ha llamado la atención en esta novela, la palabra hambre es casi tan frecuente como las ocurrencias del vocabulario abyecto. No se describen los efectos psicológicos o físicos del hambre; el narrador se limita a repetir el vocablo que se encuentra en frases iguales de escuálidas, a modo 
de reflejo estilístico. Por supuesto, la obsesión famélica recuerda la picaresca, con la que se entabla una relación intertextual. Al igual que Lazarillo pasa de un amo a otro, Rey va de una mujer a otra, aunque Magda constituye la excepción: siempre vuelve hacia ella. Lo que mueve al pícaro y a Rey es el estómago. Siempre está en busca de satisfacer esta necesidad básica. Es el hambre (y no el deseo sexual) lo que mueve a Rey a pasar de una mujer a otra. La secuencia no es comida como pre-texto, pre-ludio de sexo, sino que se invierte: el sexo es el medio de obtener comida. Rey no paga con dinero sino con su pinga de oro. Las veladas alusiones al sexo presentes en las novelas picarescas se explicitan aquí de una manera sórdida.

A diferencia de la picaresca, el hambre no es metáfora de una búsqueda espiritual ni representa la búsqueda del amo/padre. Pero si leemos de manera detenida, podemos ver una búsqueda de la madre en Rey. No solo las diferentes mujeres que lo mantienen hacen las veces de madres sustitutas, sino que la palabra hambre es asociada por Rey a su madre biológica. Rey recuerda de manera explícita las palabras de su mamá que le decía que se olvidara del hambre para burlarla. "No le hagas caso al hambre polque no hay na' que comer". Esa frase de su madre la repetía automáticamente y se le quitaba el hambre. Lo hacía como un reflejo condicionado. Así de simple" (113). La madre es asociada a la ausencia, lo negativo, y no a la imagen consabida de dulzura y protección, que tendría su expresión más clara en la leche materna que recibe el hijo. La leche de la madre es sustituida por la leche de Rey, el semen. No la da para reproducir (salvo al final de la novela cuando se ilusiona con dejar embarazada a Magda), sino para dejar de tener hambre, gozar el momento y a la vez mostrar su dominio masculino. A lo largo de la novela Rey quiere deshacerse de esta atadura con el pasado, concretada en el recuerdo de la frase de la madre sobre el hambre, pero el deseo de quitar el hambre (y la sed) lo dominará hasta el final.

Opino, por tanto, que El Rey de La Habana es más que un juego con estereotipos, que están presentes sin duda. El libro incita al lector a reflexionar sobre cuestiones ontológicas (esse en latín se asocia tanto con edo como con sum) y filosóficas: ¿Esta novela puede ser la representación de la realidad? ¿Cómo se sobrevive en el margen? ¿ ¿Se puede vivir al minuto y sin ética? ¿Hasta qué punto es tragable lo abyecto? ${ }_{\mathrm{C}}$ Qué implica el hambre? $\mathrm{i}$ Dónde ubicar la frontera entre lo animal y lo humano? ¿Cómo repensar el cuerpo y la bestialidad? La intertextualidad con la picaresca intensifica esta dimensión más amplia del libro.

En su comentario de la película/documental Suite Habana (2003), Dara Goldman (879) la compara brevemente con El Rey de La Habana y Trilogía sucia de La Habana de Gutiérrez. Según Goldman ambos artistas presentan el lado oculto de la cotidianidad habanera, invisible para los turistas, sin machacar en 
el contexto revolucionario (ni condenándolo ni reivindicándolo (Bouffartigue 146)). En Suite Habana, Fernando Pérez (n. 1944) reconstruye un día de unos diez habaneros comunes y corrientes, como de la manisera Amanda o del niño con síndrome de Down. A causa de la ambientación en una Habana en ruinas, otro cliché del Período Especial, el filme "parece situado en pleno Período Especial" (Serra 99), aunque la presencia de la estatua de John Lennon en el Vedado, uno de los leitmotiv, la ubica después de diciembre de 2000, fecha de su inauguración. Para evocar a los personajes el cineasta recurre a la fotografía, la banda sonora, el creativo aprovechamiento de los sonidos de ambiente y el montaje, pero están ausentes los diálogos. Hay largos primeros planos de los actos físicos ejecutados por los protagonistas, identificados por su nombre y su edad. En un epílogo, se proyecta a los diferentes personajes con subtítulos que formulan los sueños de cada personaje. Estos sueños, un eco de la canción de John Lennon "Imagine", casi siempre están relacionados con un logro artístico. La película se propone resaltar lo que de paradójicamente poético puede haber en una realidad signada por la precariedad material e indaga mediante un montaje sutil de imágenes en la individualidad de los diferentes personajes. En los diferentes momentos de comida que estructuran en parte la película, se estetizan los actos cotidianos como el proceso de escoger el arroz y los frijoles, la cebolla que se corta en lascas, los ajos que se machacan, el maní que se tuesta y se mete en cucuruchos... Se filman la miseria y la pobreza con dignidad, a veces combinadas con un tono nostálgico. Por ejemplo, en la cena frugal de arroz, frijoles y boniato que el esposo enfermo y la Manisera malcomen despaciosamente, vemos que sobre la mesa cuelga el retrato de su boda, en el que se ven considerablemente más jóvenes y sonrientes, detrás del pastel nupcial a punto de ser picado, recuerdo de tiempos mejores.

Algunos críticos hacen una lectura ideológica del filme, considerando los esfuerzos por sobrevivir como sacrificios necesarios para preservar la Revolución en el sentido de "Yes, we still can". De acuerdo con los preceptos propugnados por el brasileño Glauber Rocha y las ideas del Tercer Cine en general, se podría postular que la película propone una estética del hambre, es decir, un tratamiento ético de la pobreza y de la exclusión, aunque no acude a la violencia explícita tal como lo propone Rocha. A la vez, la presencia de los sueños en casi cada personaje, el montaje sutilmente lírico de toda la miseria en esta suite, la música bien escogida, los primeros planos impactantes, los colores y el tono sepia al final convierten la película a veces en un discurso casi celebratorio de la penuria. La espectaculariza y la glamouriza, convirtiéndola en objeto consumible, de manera que presenciamos en ciertos momentos una cosmética del hambre (Bentes). Pérez embellece el hambre, mientras que Gutiérrez la afea. En ambos casos, esto 
provoca planteamientos de índole filosófica y artística de cómo representar la pobreza y al individuo en situaciones de escasez.

El último ejemplo que quisiera comentar reúne y rebasa las estrategias anteriores de estereotipos, oposición, relegación y metonimia que he venido comentado. Me refiero a un pequeño ensayo, Las comidas profundas de Antonio José Ponte, cubano exiliado en Madrid desde 2007. Lo escribió en 1996 cuando aún estaba viviendo en Cuba. El texto es una meditación sobre el deseo de comida en un contexto de penuria, pues la portada engaña. Desde la primera página el yo narrador subraya la ausencia de comida real, solo representada en el hule de la mesa donde hay "frutas y carne asada y copas y botellas, todo lo que no tengo" (7). A diferencia del texto de Gutiérrez, aquí la palabra hambre está casi ausente. Para evocarla el narrador va ensartando una serie de reflexiones heterogéneas basadas en reminiscencias literarias y personales donde la comida es evocada en su ausencia. Aunque el texto parte de "una mesa en La Habana", heptasílabo que constituye el séptimo capítulo, no se ciñe a Cuba, se expande en el tiempo y en el espacio. Incorpora tanto evocaciones de Carlos V, quien huele la piña, pero no la prueba, como un fragmento de un diario de Virginia Woolf en tiempos de la Segunda Guerra Mundial.

Esto no impide que las referencias a Cuba y al Período Especial se infiltren en el ensayo de manera sutil. Las meditaciones se originan a veces a partir de la ausencia de comida identitaria, como la piña que Carlos V no comió, sino solo olió, el ajiaco como símbolo de la mezcla racial a la manera de Ortiz, o las viandas (tubérculos) no encontradas en Madrid. Incluso se incorpora la anécdota del bistec de frazada, este ejemplo tan estrambótico del Special Period Exotic que he mencionado. Pero Ponte recoloca la historia de la conversión de la tela en bistec en un conjunto de textos ficcionales buscándole un sentido más profundo y más amplio, menos ligado a lo circundante, sin por ello dejar de adoptar una actitud cáustica. Equipara la ingestión del bistec de frazada a la ingestión de un zapato de una mujer adorada, historia contada por Apollinaire en su libro Les diables amoureux. Comenta el narrador: "[Las dos historias de Apollinaire Sustituyen, igualan, es decir, metaforizan" (Ponte 28). Y agrega:

Moralismos aparte, la historia de la carne falsa habla también de la búsqueda de metáforas mediante la comida. Las provisiones estatales cubanas participan también en este metamorfizar y el café tiene un sumando importante de otros granos tostados, la carne es extendida con soya. [...].

La historia se repite en cualquier país en depresión económica. La desesperación hace que se multipliquen las metáforas. (29-30) 
Para el narrador, escribir sobre comida es un castillo en España, traducción de un château en Espagne, es decir, una quimera. Desde un punto de vista metaliterario, la idea básica de este ensayo podría consistir en que solo se puede hablar de comida en su ausencia, citando otros textos, palabras que carecen de su dimensión referencial. Ponte sabe que su mundo solo se cimienta en palabras, incluso si han dejado de tener referente. Por eso juega desplazando textos y contextos en un perpetuo diálogo poético, consciente de la carencia y de la negación de la plenitud. Por eso Ponte tiende "puentes" hacia otros escritores, se rodea de autores que escribieron sobre la comida y que son su comida. Confunde "sílabas con bocados", hace "comidas en palabras" (35-36). Por eso procede por asociaciones, implicaciones metafóricas y metonímicas, en busca de un agarre, un origen para siempre perdido. La ausencia de comida, el vacío provoca la abundancia verbal, y por qué no usar la palabra tan frecuente en un contexto caribeño, engendra barroquismo. La abundancia y la carencia son complementarias:

El que escribe sobre la mesa con mantel de comidas dibujadas parece tan desprovisto de materia como si se dispusiera a un ejercicio de recogimiento. Escribe en una celda acerca de comidas. Porque tiene muy pocas concreciones a su alrededor cree merecer un poco de abstracción. Tiene la barriga en blanco y las carencias le ayudan a pensar que toda comida es sustitutiva, que comer es siempre metaforizar, tender un puente. Todo es remedo de la leche materna, de aquello que cruzaba la tripa del ombligo, de la neblina que al inicio... (Ponte 31)

Con estos puntos suspensivos he llegado al final de mi recorrido. Los ejemplos comentados muestran que el análisis de las referencias culinarias va más allá de las consabidas connotaciones. La connotación identitaria está presente, pero no lo explica todo: el deseo idiosincrático de obtener carne no se reduce a introducir invenciones originales. El hambre y la escasez tampoco pueden ser explicadas únicamente desde el punto de vista social: el profesor en la obra de Menéndez y el Rey pobre en la novela de Gutiérrez se enfrentan a los mismos problemas de sustento en un contexto donde tendrían que ser abolidas las clases. No es suficiente recurrir a una explicación política: los estereotipos sobre la comida no solo son explotados por los escritores en el exilio. En otras palabras, la gastrocrítica en relación con el hambre en el Período Especial es más que Castrocrítica, usando un juego de palabras poco original.

Es cierto que las cuatro estrategias son más bien previsibles. Las referencias culinarias representan con frecuencia situaciones extremas: hambre o abundancia, fiesta o escasez. La exageración que lleva a estereotipos o el contraste entre abundancia y escasez son modalidades frecuentes. Al otro lado, el olvido aparente y 
las estrategias metonímicas presentan una manera más ambigua de tratar el hambre. Cuestionan de manera más profunda la función de la literatura en relación con el mundo referencial/material. Por tanto, la gastrocrítica es una cuestión de poética, ética y estética. La poética de los escritores influirá necesariamente en la manera de enfocar el tema. El sarcasmo de Valdés, la introspección tan característica de Suárez, la actitud escéptica de Portela, el interés de Menéndez por la novela negra, el realismo sucio de Gutiérrez, el enfoque poético y ensayístico de Ponte marcan la manera de bregar con el hambre. En lo ético, nos incita a reflexionar sobre problemas esenciales, por ejemplo, la frontera entre lo humano y lo animal o entre el bien y el mal, y el sentido de la vida. La gastrocrítica implica también una estética, porque la incorporación de referencias culinarias suscita la pregunta de cómo escribir y cómo hacer que este fenómeno tan cotidiano nos llegue desde el texto a los ojos y a los sentidos.

\section{Obras citadas}

Alicia en el Pueblo de Maravillas. Dir. Daniel Díaz Torres. ICAIC, 1991. DVD.

Alonso, Nancy. "César". Cerrado por reparación. La Habana: Ediciones Unión, 2002. 12-20. Impreso.

Arellano, Robert. Havana Lunar. Nueva York: Akashic Books, 2009. Impreso.

Bakhtin, Michael. L'oeuvre de François Rabelais et la culture populaire au Moyen Age et sous la Renaissance. París: Gallimard, 197o. Impreso.

Barthes, Roland. "Lecture de Brillat-Savarin". Essais critiques IV. París: Seuil, 1984. 303-326. Impreso.

Benítez Rojo, Antonio. "Entrevista con Antonio Benítez Rojo: Amherst, Massachusetts (28 de julio 2003)". Por Eduardo San José Vázquez. Caribe IX.1: 85-108. Impreso.

Bentes, Ivana. "Ciudade de Deus promove turismo no inferno". 9 agosto 2003. Web. 8 mayo 2015.

Bouffartigue, Sylvie. "Suite Habana: la recherche de l'accord parfait". Le cinéma cubain: identité et regards de l'intérieur. Ed. Sandra Hernández. Nantes: CRINI/Université de Nantes, 2006. 137-149. Impreso.

Bourdieu, Pierre. La distinction: critique sociale du jugement. París: Minuit, 1979. Impreso. Carpentier, Alejo. "Problemática de la actual novela latinoamericana". Tientos y diferencias. Barcelona: Plaza y Janés, 1987. 7-28. Impreso.

De Certeau, Michel, Luce Giard, y Pierre Mayol. L'invention du quotidien: 2. Habiter, cuisiner. París: Folio, 1994. Impreso.

De Ferrari, Guillermina. “Abjection and Aesthetic Violence in Pedro Juan Gutiérrez's Trilogía sucia de La Habana". Vulnerable States: Bodies of Memory in Contemporary 
Caribbean Fiction. Charlottesville/Londres: University of Virginia Press, 2007. 181210. Impreso.

De Maeseneer, Rita. El festín de Alejo Carpentier: una lectura culinario-intertextual. Genève: Droz, 2003. Impreso.

Ferré, Rosario. "La cocina de la escritura". La sartén por el mango: encuentro de escritoras latinoamericanas. Ed. Patricia Elena González y Eliana Ortega. Puerto Rico: Huracán, 1985. 137-54. Impreso.

García Márquez, Gabriel. "Entrevista". Por Rita Guibert. Seven Voices: Seven Latin American Writers talk to Rita Guibert. Nueva York: Alfred Knopf, 1973. 305-337. Impreso.

Goldman, Dara. "Urban Desires: Melancholia and Fernando Pérez's Portrayal of Havana". Bulletin of Hispanic Studies 85 (2008): 867-881. Impreso.

Gutiérrez, Pedro Juan. El Rey de La Habana. Barcelona: Anagrama, 1999. Impreso. Jeanneret, Michel. Des mets et des mots: Banquets et propos de table à la Renaissance. París: José Corti, 1987. Impreso.

Lévi-Strauss, Claude. "The Culinary Triangle". Food and Culture: A Reader. Ed. Carole Counihan and Penny Van Esterik. Londres: Routledge, 1997. 28-35. Impreso.

Madagascar. Dir. Fernando Pérez. Wanda Vision \& ICAIC, 1994. DVD.

Menéndez, Ronaldo. Las bestias. Madrid: Lengua de Trapo, 2006. Impreso.

Obejas, Achy. Ruins. Nueva York: Akaschic, 2009. Impreso.

Ortiz, Fernando. "Los factores humanos de la cubanidad". In La isla infinita de Fernando Ortiz. Ed. Antonio Fernández Ferrer. Alicante: Instituto de Cultura "Juan Gil-Albert", 1998. 187-207. Impreso.

Ponte, Antonio José. Las comidas profundas. Angers: Deleatur, 1997. Impreso.

Portela, Ena Lucía. La sombra del caminante. La Habana: Ediciones Unión, 2001. Impreso.

"Literatura versus lechuguitas: breve esbozo de una tendencia". Voces para cerrar un siglo I. Ed. René Vázquez Díaz. Estocolomo: Skogs Grafiska, 1999· 70-79. Impreso.

Quintero Herencia, Juan Carlos. "No es lo mismo llamar al cimarrón, que verlo huir." La Torre 10.35 (2005): 1-28. Impreso.

Rocha, Glauber. "Uma estética da fome". Revista da Civilização Brasileira 3 (1965): 165-17o. Impreso.

Serra, Ana. "La Habana cotidiana: espacio urbano en el cine de Fernando Pérez". Chasqui 35.1 (2006): 88-105. Impreso.

Suárez, Karla. Silencios. Madrid: Santillana, 2008. Impreso.

Suite Habana. Dir. Fernando Pérez. Wanda Vision \& ICAIC, 2003. DVD. 
Teja, Ada. "Bajtín y los banquetes de Lezama". Revista de literatura cubana XI.21 (1993): 78-99. Impreso.

"El banquete, la muerte y la comedia". Codici del gusto. Ed. Maria Grazia Profeti. Milano: Francoangeli, 1992. 466-486. Impreso.

Tobin, Ronald W. “Qu'est-ce que la gastrocritique?" XVIIe siècle 217.4 (2002): 621-630. Impreso. Tarte à la crème: Comedy and Gastronomie in Molière's Theater. Columbus: Ohio State University Press, 1990. Impreso.

Vadillo, Alicia. The Culinary Text as Constructive Strategy in the Work of Three Contemporary Writers: Severo Sarduy, fosé Lezama Lima and Alejo Carpentier. Ph.D. University of Syracuse. Michigan: Ann Arbor, 1996. Impreso.

Valdés, Zoé. Te di la vida entera. Barcelona: Planeta, 1997. Impreso.

Vázquez Díaz, René. "Macho grande en el balcón”. El pez sabe que la lombriz oculta un anzuelo. Barcelona: Icaria, 2009. 25-41. Impreso.

Vázquez Montalbán, Manuel. "Las comidas profundas". El País Semanal 23 marzo 2008: 46-48. Impreso.

Whitfield, Esther. Cuban Currency: The Dollar and 'Special Period' Fiction. Minneapolis: Minnesota Press, 2008. Impreso.

Wilkinson, Stephen. Detective Fiction in Cuban Society and Culture. Bern: Peter Lang, 2006. Impreso. 